\title{
El futuro de la radio musical en el entorno digital en Argentina y España
}

The future of music radio in the digital environment in Argentina and Spain

María del Pilar Martínez-Costa, Universidad de Navarra, marcosta@unav.es

María José Müller, Universidad Austral, mmuller@austral.edu.ar

Resumen

El objeto de este trabajo es describir y analizar la evolución de la escucha de las principales emisoras musicales españolas y argentinas. Desde el análisis de la evolución del comportamiento del consumo que ofrecen los principales estudios disponibles, se dibuja un mapa del sector. El estudio revela que las principales emisoras musicales pierden progresivamente audiencia, y que esta audiencia envejece. Por este motivo los formatos basados en éxitos contemporáneos (CHR) pierden más audiencias y más rápidamente; mientras que los especializados en formatos más específicos -rock o música nacional, por ejemplo- que están dirigidos a audiencias adultas, consiguen crecer. Por otra parte, el trabajo muestra que la estrategia de las emisoras musicales en sus ventanas online no ha conseguido recoger el impacto de audiencia esperado hasta el momento.

Palabras clave

Radio musical, audiencias radio, usuarios.

Abstract

The purpose of this paper is to describe and analyze the evolution of listening to the main Spanish and Argentine music stations. From the analysis of the evolution of consumer behavior offered by the available studies, it is drawn a map of the sector. The study reveals that the music stations progressively lose audience, and that audience is aging. For this reason the formats based on Contemporary Hits (CHR) lose more hearings and more quickly; while more specialized in specific formats -rock or country music, for example- that are aimed at adult audiences, they manage to grow. Moreover, the work shows that the strategy of music stations on the web is not gathered the audience impact expected at the moment.

Keywords

Music radio, radio listerners, users.

Sumario

1. Introducción. El viejo modelo a debate. 2. Objetivos y metodología. 3. Antecedentes y marco teórico. 4. Resultados. 5. Conclusiones: Hacia un nuevo modelo de radio musical. 6. Bibliografía.

\footnotetext{
${ }^{1}$ El presente estudio forma parte del Proyecto de Investigación "Usos y preferencias informativas en el nuevo mapa de medios en España: audiencias, empresas, contenidos y gestión de la reputación en un entorno multipantalla" cofinanciado por el Ministerio de Economía y Competitividad y el Fondo Europeo de Desarrollo Regional (FEDER), CSO2015-64662-C4-1-R MINECO/FEDER, UE (2016/2018), y de la actividad desarrollada por el Observatorio de Innovación Radiofónica, creado en el marco del Acuerdo de Investigación y Producción de Contenidos establecido entre la Universidad Austral, la Universidad de Navarra y la empresa Mitre S.A. en abril de 2015.
} 


\section{Introducción: el viejo modelo a debate}

La irrupción de la tecnología digital, el crecimiento de la movilidad y el auge de los medios sociales ha revolucionado el modelo y la cultura de consumo de los medios de comunicación tradicionales. Aunque el cambio está inducido por la tecnología, su naturaleza es más profunda: tiene que ver con los nuevos modos en los se produce, se distribuye y se consume la información. Las audiencias de hoy no solo escuchan buenas historias, sino que generan contenidos, comparten experiencias y amplifican la distribución por canales sociales no controlados directamente por los radiodifusores. De esta forma, la audiencia pasa a estar en el centro neurálgico de todos los procesos de la comunicación radiofónica.

Además, los estudios de mercado muestran que las audiencias están cambiando de forma muy rápida, en algunos casos sin contar con los medios tradicionales. Por ello, los esfuerzos de innovación de las empresas de radio buscan mejorar la experiencia de los públicos, que se constituyen en comunidades de relaciones.

La radio parte con ventaja en este nuevo escenario, ya que sigue siendo un espacio privilegiado de complicidad, de proximidad y de interacción personal con su audiencia. Sin abandonar esta ventaja tradicional, la radio tiene que hacer un esfuerzo por extender las fórmulas de conversación, pero aportando valor, o sea contenidos y servicios, a esas comunidades de relaciones personalizadas, horizontales, cambiantes, activas, diacrónicas, fragmentadas, implicadas y expandidas que ofrecen los medios sociales. Todo lo contrario a las audiencias masivas, verticales, pasivas, sincrónicas, lineales, anónimas y sintéticas del modelo de audiencia tradicional que no para de perder adeptos. Ha llegado el tiempo de abandonar la estrategia de contar y sumar audiencias masivas para poner en valor las audiencias indirectas y empezar a construir comunidades (Martínez-Costa y Prata, 2016).

La radio musical no escapa a este planteamiento. Además, debe hacer frente a los cambios producidos en el negocio de producción y la distribución musical, y a la presencia de las plataformas tecnológicas globales de distribución, que compiten por el tiempo de los usuarios, sobre todo de la audiencia favorita de la investigación de mercado, los millennials. La radio musical empieza a perder audiencia y mantiene formatos de programación que no han sido "refrescados" al ritmo del cambio de los usos y preferencias de consumo.

\section{Objetivos y metodología}

En este contexto, el objeto de este trabajo es describir y analizar la evolución de la escucha de las principales emisoras musicales españolas y argentinas. Desde el estudio de la evolución del consumo de los tipos de programación, se espera tener una radiografía del sector y responder a algunas de las siguientes preguntas: ¿Quién escucha la oferta de contenidos de la radio musical actual? ¿Las emisoras musicales de los grupos y marcas de radio más importantes, los que aglutinan aún grandes audiencias, mantienen un modelo de contenidos acorde a los nuevos públicos? ¿Hay síntomas de cambio? ¿Tiene futuro la radio musical en un mercado de audio bajo demanda donde los contenidos musicales circulan sin la intermediación de un radiodifusor? ¿Qué valor puede añadir la radio musical en un entorno de multiplicación de servicios de audio musical?

Para ello, se sistematizarán y analizarán los datos de los estudios de audiencia de las 5 emisoras musicales más escuchadas, proporcionados por el Estudio General de Medios (EGM) en España y por Kantar IBOPE Media en Argentina. Se comparará estos datos con su modelo de programación, tanto offline como online, destacando algunas de las estrategias puestas en marcha para diversificar la oferta ante la aparición de la nueva competencia.

De esta forma, se sentarán las bases para definir un nuevo modelo de radio musical basado en los nuevos perfiles de audiencia y tendencias de consumo.

\section{Antecedentes y marco teórico}

Desde su origen la música ha sido parte de la radio. Como contenido de un programa y como parte del lenguaje radiofónico, la música estuvo presente desde las primeras transmisiones radiofónicas. Sin embargo, debieron pasar varias décadas hasta que la música diera lugar a una estrategia programática y se generalizaran los modelos de radio especializados.

El origen de la radio musical hay que situarlo a mediados de los años cincuenta del siglo XX, cuando irrumpe el Top 40 como primera expresión. Entre 1953 y 1956, tres emisoras locales de Estados Unidos -KOWH de Omaha, KLFI de Dallas y WOKY de Milwaukee- comenzaron a emitir de forma constante y reiterativa la actualidad discográfica, dando lugar a un nuevo modo de hacer y entender la radio, basado en las preferencias musicales e informativas de grupos específicos de públicos (Moreno, 1999: 91).

En Europa y el resto de América, este nuevo concepto de radio tardaría una década en llegar. El nacimiento de la industria discográfica, la aparición de la juventud como un sector social y cultural emergente y la implantación progresiva de la FM en los años sesenta impulsaron la ideación y producción de una programación diferente. También ayudaron la crisis del modelo de radio generalista ante la irrupción de la televisión, el aumento del número de emisoras, la fragmentación del mercado publicitario y el nacimiento de nuevas corrientes de música popular. En ese entorno poco ventajoso para la radio, la difusión de música era un recurso de bajo coste productivo y menor riesgo de explotación comercial. En ese momento, como señala Martí, la música deja de ser un contenido más y un elemento distintivo de la marca de la emisora, para comenzar a definir una nueva radio y dar paso al inicio de la radio comercial moderna (2004: 26 y 33).

Como se ve, la radio musical marcó el origen de la radio especializada, ya que sus inicios estuvieron vinculados a la demanda y gustos musicales. Aquellas primeras fórmulas musicales fueron consideradas como paradigma de la especialización radiofónica (Martí, 2004: 33). Solo a partir de los años setenta y ochenta la especialización se extendería a contenidos y temáticas diferentes, 
atendiendo a las características sociales y culturales de la audiencia a la que se quería llegar. Entonces, se consolida el modelo de radio especializada que Moreno define como "la estrategia empresarial y programática que se basa en la comunicación y/o información de un área del conocimiento determinada para apelar a un segmento específico de la audiencia potencial de la emisora con un producto radiofónico exclusivo. Se caracteriza por la sectorización de los contenidos y la segmentación de la audiencia" (2005: 69).

La radio musical es, por tanto, un tipo de radio especializada cuyo relato se construye principalmente a través de la difusión de música, generalmente de un estilo, género o década específicos. Puede incluir en su relato continuidad informativa y de servicio, y programas de entretenimiento, con presencia de palabra, pero siempre en un relato coherente al estilo musical y a los ritmos vitales de la audiencia a la que se dirige.

Algunos autores como Martí (1990 y 2004), Moreno (1999 y 2005) y Pedrero (2000) distinguen entre la radio especializada musical, temática musical, fórmula musical y de formato cerrado. Sin insistir sobre estas distinciones necesarias y justificadas por el devenir histórico de este modelo de programación, aquí interesa destacar que en la actualidad, la radio musical ha evolucionado progresivamente a un modelo mixto o híbrido que suma programas, información y servicios.

Antes de la irrupción de las nuevas plataformas de distribución de música, Martí ya señalaba que, pese a seguir orientados a un target de audiencia concreto, estos formatos híbridos aparecen a finales de los años noventa para incorporar variaciones según el segmento horario de la jornada, la actividad que realiza la audiencia y sus intereses, y así dotar a la programación de mayor flexibilidad (2000: 242 y 243). Se revaloriza la figura del DJ como presentador y prescriptor de música y aparecen programas-faro destinados a momentos en los que la audiencia demanda otra estructura de programación. Desde entonces, los programas despertadores o morning shows y los programas del drive time vespertino se han consolidado como un ingrediente de la radio musical que persigue involucrar a la audiencia joven y atraer publicidad, y, más recientemente, diferenciarse de los servicios de audio bajo demanda (Alonso González 2015: 692).

Además, atendiendo a las demandas cambiantes y cada vez más heterogéneas de la audiencia, la radio musical se ha impuesto la revisión periódica del contenido principal. El Top 40 ha dado paso a diferentes variaciones de los formatos Adulto Contemporáneos (AC), y las músicas del pop y rock nacional ganan terreno en la mayoría de los mercados. Además, se persigue extender las especializaciones hacia los gustos y preferencias del target joven adulto, de 35 a 44 años, ante el desinterés por la radio como medio de comunicación que manifiestan los públicos más jóvenes (Gutiérrez et al., 2011 y López Vidales et al., 2014).

Si esta ha sido la tendencia hasta ahora desde el punto de vista del contenido y la estrategia programática, desde el punto de vista del negocio la radio musical ha tenido que revisar su modelo y ampliar su actividad al sector del entretenimiento. Ante la multiplicación de competidores que permite la tecnología y la ampliación de un mercado abierto a lo global, la radio musical ha extendido su actividad a la grabación, producción, distribución y gestión de eventos y publicaciones relacionados con la música (Martínez-Costa 2004: 342). Tendencia que se ha acentuado en la última década dando lugar a nuevas formas de comercialización y diversificación del contenido.

También el modelo de consumo experimenta cambios. Como antes se mencionaba, la radio tiene que hacer un esfuerzo por trabajar las fórmulas de conversación de los entornos digitales, aportando nuevos servicios a esas las comunidades de relaciones que ofrecen los medios sociales (Martínez-Costa y Prata, 2016). Desde la confección de listas de reproducción de música hasta los menús de radios a la carta confeccionados según autor, estilo, actividad a realizar y estado de ánimo, hay un abanico de nuevas opciones que las emisoras musicales han ido incorporando a partir de los nuevos gustos y preferencias de los oyentes. Sin embargo, a pesar de este esfuerzo por transformarse en marcas de referencia multiplataforma, la audiencia de radio musical de la antena tradicional se estanca, envejece y pierde oyentes de forma gradual. Cuestión que se analizará en los siguientes apartados para los casos de las principales emisoras musicales de España y Argentina.

\section{Resultados.}

\subsection{El mercado de la radio musical en España.}

La prehistoria de la radio musical en España arranca con los inicios del medio, cuando el contenido de aquellas primeras emisiones eran retransmisiones de recitales en directo. Hubo además numerosos programas especializados que encontraron en el disco un recurso útil para la producción de contenidos. Sin embargo, la radio musical da los primeros pasos en España con la expansión de la música popular y sobre todo con dos programas emblemáticos que la difundían: "Discomanía" de Raúl Matas (1959) y "El gran musical" de Tomás Martín Blanco (1963). Ambos programas eran de Radio Madrid de la Cadena SER y tenían por objetivo dar a conocer las novedades discográficas con emisiones de cara al público, entrevistas y actuaciones en directo (Balsebre, 2002: 459).

Tras el éxito sobre todo de "El gran musical" que llegaba a reunir dos centenares de jóvenes en el estudio durante las emisiones, Radio Madrid encarga a Rafael Revert en 1966 la puesta en el aire de un programa de radio basado en el modelo del Top 40 norteamericano. Era un programa de dos horas en el que sonaban Los40 discos preferidos de Revert, que luego sumó horas y se extendió a otras ciudades (Pedrero, 2000: 46). Nace entonces "Los40 principales" como un programa. En 1978 con la puesta en marcha de las nuevas emisoras de FM se transformará en la primera emisora de radio musical en España (Faus, 2007: 872). Hoy, bajo la marca Los40 y tras 50 años, es la emisora de radio especializada de mayor audiencia, se ha diversificado en una variedad de canales de consumo, y se define como una marca multiplataforma con una comunidad social que supera los 20 millones de usuarios. 


\subsubsection{La oferta de emisoras musicales más escuchadas en España.}

Los40 compite desde los años ochenta con un abanico variado de emisoras que se fueron sumando a la oferta de radio musical. Dial, Cadena100, Europa FM y Rock FM completan la lista de las cinco emisoras más escuchadas en la actualidad.

Tabla 1: Descripción de las cinco emisoras musicales más escuchadas en España, 2015

\begin{tabular}{|c|c|c|c|c|c|}
\hline & Los40 & Dial & C100 & Europa FM & Rock \\
\hline Tipo de emisora & Comercial & Comercial & Comercial & Comercial & Comercial \\
\hline Titularidad & Grupo Prisa & Grupo Prisa & Cadena COPE & Atresmedia & Cadena COPE \\
\hline Programación & $\mathrm{CHR}$ & AC/Español & AC/Internacional & AC/Internacional & Rock \\
\hline Ranking & 1 & 2 & 3 & 4 & 5 \\
\hline Cuota audiencia & 15,1 & 13,4 & 10 & 9,5 & 5,7 \\
\hline Target & Joven & Adulto & Joven/adulto & Joven & Joven/adulto \\
\hline $\begin{array}{l}\text { Hora mas } \\
\text { escuchada }\end{array}$ & $9-10 \mathrm{AM}$ & $10-11 \mathrm{AM}$ & 8-9 AM & 8-9 AM & $10-11 \mathrm{AM}$ \\
\hline $\begin{array}{l}\text { Programa más } \\
\text { escuchado }\end{array}$ & Anda Ya & Atrévete & $\begin{array}{c}\text { ¡Buenos días Javi y } \\
\text { Mar! }\end{array}$ & $\begin{array}{l}\text { Levántate y } \\
\text { Cárdenas }\end{array}$ & $\begin{array}{c}\text { El Pirata y su } \\
\text { banda }\end{array}$ \\
\hline
\end{tabular}

Como ya se mencionó, Los40 nace en 1966 como un programa de radio. Gracias al éxito del programa, y al aumento de emisoras y receptores de FM, Los40 fue incrementando su duración diaria hasta llegar en 1979 a las 24 horas de emisión diarias y constituirse en una radio especializada musical. Pertenece al Grupo PRISA, al igual que Cadena SER, M80, Máxima FM, Ona FM y Radiolé. Hasta mayo de 2016, cuando cumplió 50 años de emisiones, su marca era Los40 Principales. Como marca radiofónica y bajo el eslogan global de "Music Inspires Life (La música inspira la vida)", Los40 tiene más de 136 emisoras en España, así como filiales en varios países (Argentina, Chile, Colombia, Costa Rica, Ecuador, Guatemala, México, Panamá, Paraguay y República Dominicana).

La segunda emisora musical más escuchada es Cadena Dial, también emisora propiedad del Grupo PRISA, que emite exclusivamente música en español. Cadena Dial comenzó sus emisiones en 1988 como Radio Corazón, siendo una radio local de Madrid que mezclaba espacios de belleza, psicología, consejos, trucos de cocina y noticias con música en castellano, al estilo de una revista sonora. Bajo el eslogan "Lo mejor de nuestra música", su objetivo siempre fue crear una emisora que impulsara la música en español.

Cadena 100 es una emisora radiofónica musical española que pertenece al Grupo COPE, como la cadena generalista COPE y las musicales Rock FM y MegaStar FM. Sus estudios centrales están en Madrid, aunque posee frecuencias repartidas por toda España. Su formato es Adulto Contemporáneo por lo que está orientada a las preferencias de los oyentes de 25 a 39 años. Cadena 100 empezó a emitir el 2 de mayo de 1992, cuando Rafael Revert, que había sido fundador de Los40, la puso en marcha. Desde 2006 incluye también un programa despertador: "¡Buenos días, Javi y Mar!" presentado por Javi Nieves y Mar Amate. Su eslogan es "La mejor variedad musical".

Europa FM ocupa el cuarto puesto del ranking de emisoras musicales. En la actualidad es propiedad de la empresa Atresmedia. Comenzó sus emisiones el 15 de abril de 1996 sobre las frecuencias de Onda Mini, una emisora infantil y juvenil propiedad de Francisco Gayá. La programación de esa primera emisora se basaba en una selección de éxitos musicales dirigida a un público entre 18 y 55 años. En 1999, Europa FM firmó un acuerdo de colaboración por 10 años con Onda Cero para convertirse en su radio musical de referencia, y ocupar el lugar de la anterior Onda 10. Finalmente, Onda Cero se hizo con el 100\% de Europa FM en 2002 y la relanza como emisora musical Adulto Contemporáneo, siguiendo la estela de Kiss FM, que había nacido ese mismo año y ganado audiencia rápidamente. La mayor parte de su programación actual se basa en los éxitos del pop y el rock desde la década de 1990 hasta la actualidad, reflejado en su eslogan "El mejor pop-rock del dos mil hasta hoy". Al contenido musical se añaden programas propios como "Levántate y Cárdenas", "Euroclub" y "Ponte a prueba", todos ellos dirigidos a un público entre 18 y 35 años.

Rock FM es una cadena de radio especializada en música rock que pertenece al Grupo COPE. Inició sus emisiones en 2004 con el nombre de Rock \& Gol, con una programación temática centrada en los deportes y la música rock. En 2011 cambió su nombre y formato al actual, bajo el eslogan "La casa del rock". Sin embargo, su origen se remonta al año 1989 con el programa "Popular FM" que se emitía los domingos por la tarde combinando de una forma amena y divertida los resultados de los partidos de liga con una buena selección musical. Desde el año 2006 incluye en su programación un morning show. En 2015, Rock FM se consolida como una de las cinco cadenas musicales más importantes del país rozando el millón de oyentes diarios y superándolo los fines de semana. Desplaza así a KissFM, emisora especializada de formato Adulto Contemporáneo orientada al target 25 a 55 años, que queda desde entonces como sexta emisora más escuchada del mercado español, después de haber rozado el millón y medio de oyentes poco después de su lanzamiento en 2002. 


\subsubsection{La audiencia de las radios musicales tradicionales en España.}

La oferta de radio musical en España consigue aglutinar al 59\% de la audiencia de radio superando en escucha a la radio generalista desde 2009. El los últimos cinco años se ha consolidado esta diferencia como se refleja en el Gráfico 1.

Gráfico 1: Evolución audiencias radio en España según modelo de programación, por miles

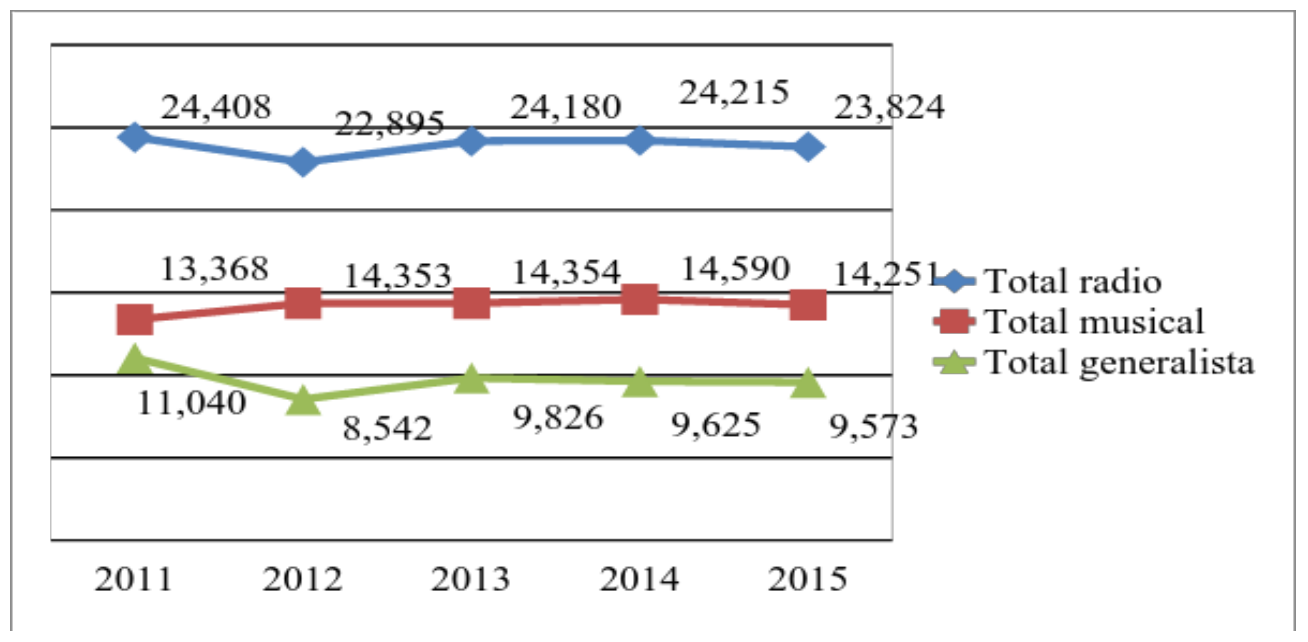

Fuente: Estudio General de Medios, AIMC (2016)

Por cadenas, Los40 es la emisora líder, aunque como se refleja en el Gráfico 2 ha perdido 900 mil oyentes desde el año 2012. La diferencia de más de medio millón de oyentes que la separaba de Dial, la segunda emisora en el ranking, ha disminuido a la mitad. Por su parte, Dial incrementa levemente su audiencia y la mantiene en los últimos cinco años, siendo la única en el formato AC/Español entre las líderes. Europa FM pierde oyentes desde 2012 y cede el tercer puesto a favor de Cadena 100 en 2013 que consigue en torno a 2 millones de oyentes. Finalmente, irrumpe y se coloca en quinto lugar en 2012, Rock FM que gana rápidamente audiencia y se estabiliza rozando en 2015 el millón de oyentes.

Gráfico 2: Evolución audiencias radio en España según cadenas musicales, por miles

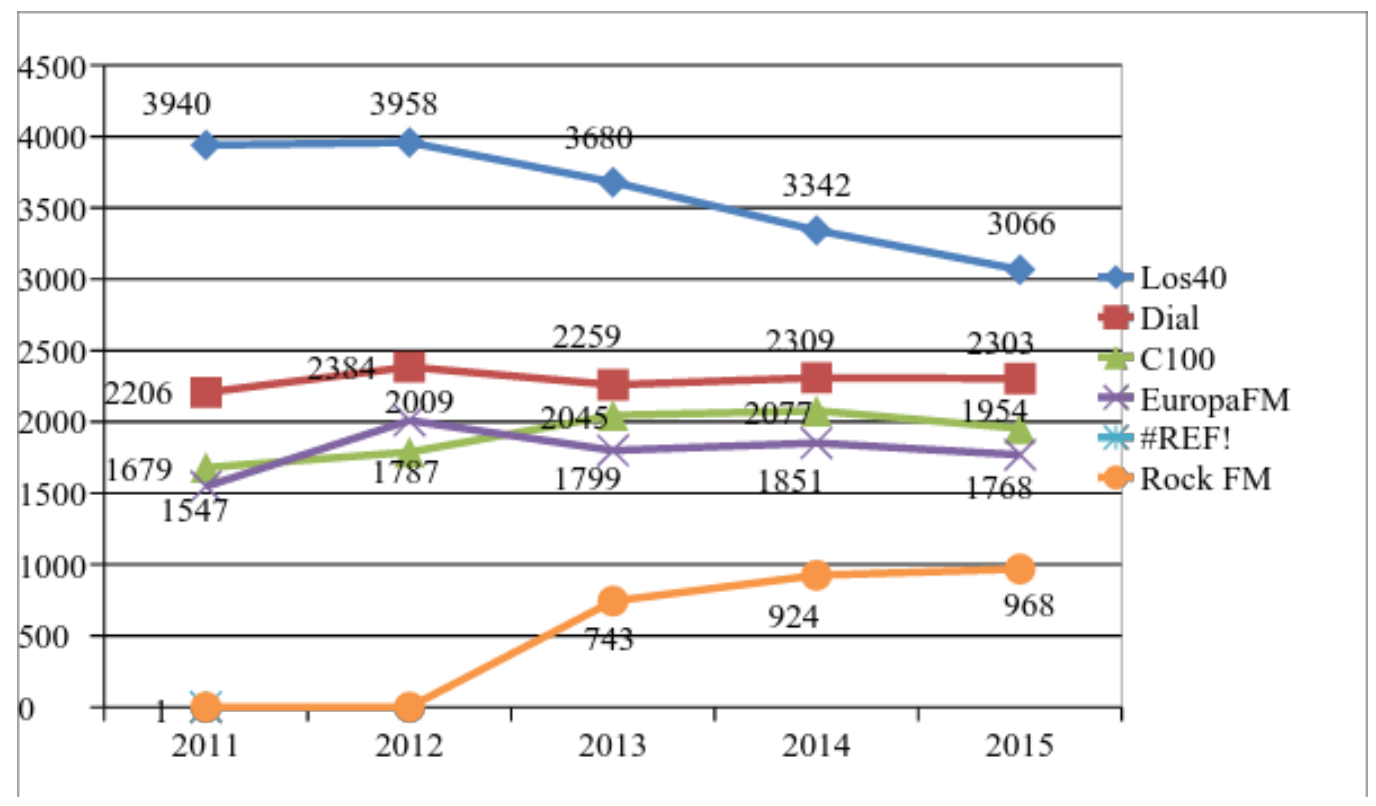

Fuente: Estudio General de Medios, AIMC (2016)

Por formatos, puede afirmarse que el CHR basado en los éxitos del momento pierde progresivamente seguidores como ocurre en otros mercados. Mientras tanto, las especializaciones de música en español y el rock mejoran, aunque hay que tener en cuenta que la competencia de la oferta es menor. El AC/Internacional consigue mantener su posición, aunque el liderazgo se discute entre varias emisoras.

Todas las emisoras combinan su especialización musical con programas despertadores o morning shows. En el Gráfico 3 se muestra la evolución de dichos programas en los últimos cinco años. "Anda Ya" de Los40 es líder aunque disminuye su 
audiencia. El programa de Dial, "Levántate” y el de Cadena 100 "¡Buenos días Javi y Mar!” son los que incrementan seguidores en el último año. "Levántate y Cárdenas" de Europa FM se mantiene en cuarto lugar con audiencia muy consolidado en torno al millón de oyentes; y Rock Fm con el programa "El pirata y su banda" incrementa progresivamente su audiencias.

Gráfico 3: Evolución audiencias morning shows cadenas musicales en España, por miles

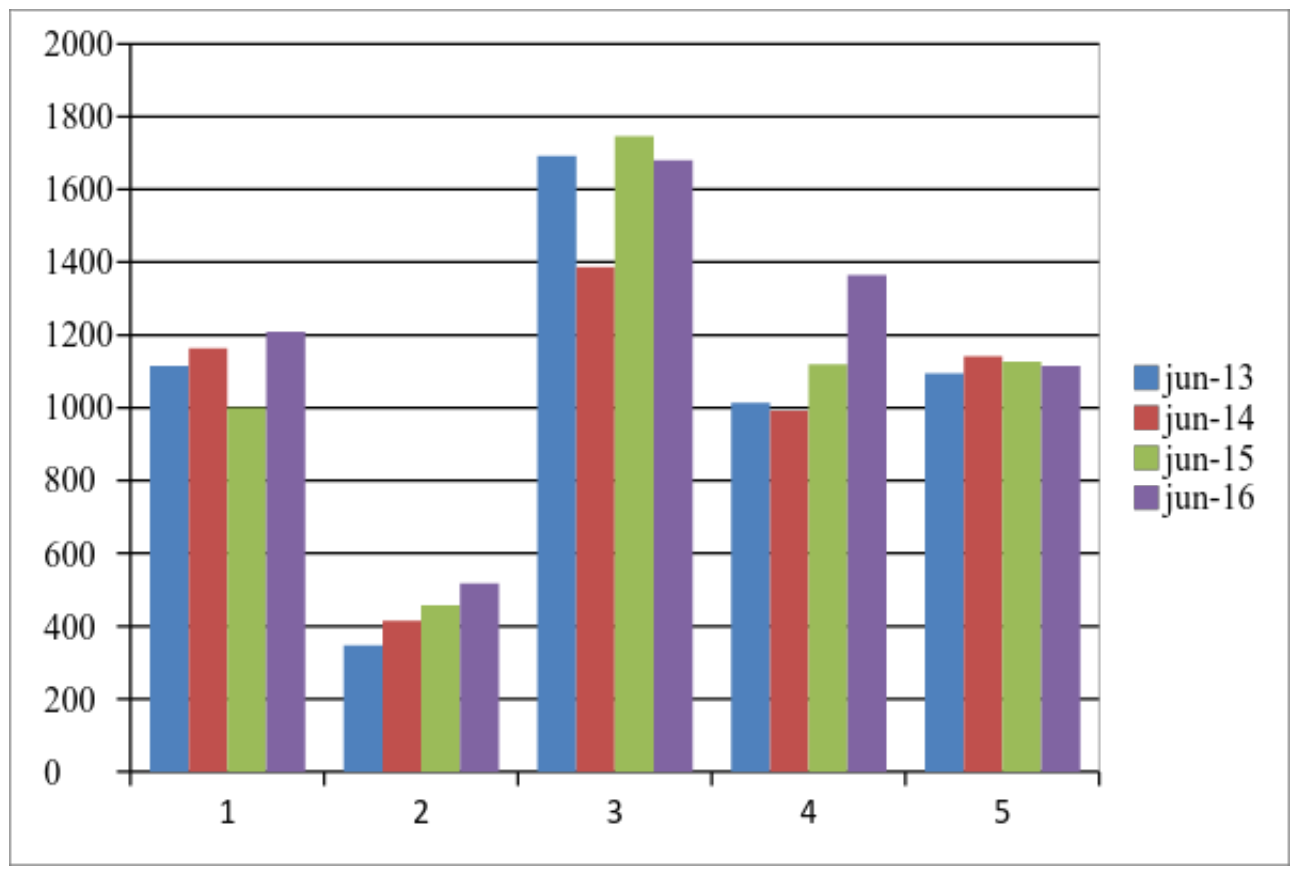

Fuente: Estudio General de Medios, AIMC (2016)

Estos programas son los responsables de sumar y arrastrar audiencia en las mañanas, de forma que el primer prime time de la radio musical se localiza entre las $8.00 \mathrm{AM}$ y las $13.00 \mathrm{PM}$, compitiendo con el prime time de la radio generalista. Por la tarde entre las 17.00 y las 19.00 PM, coincidiendo con el drive time vespertino, la audiencia nuevamente se incrementa. El Gráfico 4 muestra claramente estos dos picos de audiencia.

Gráfico 4: Audiencias cadenas musicales en España según horas del día, 2015

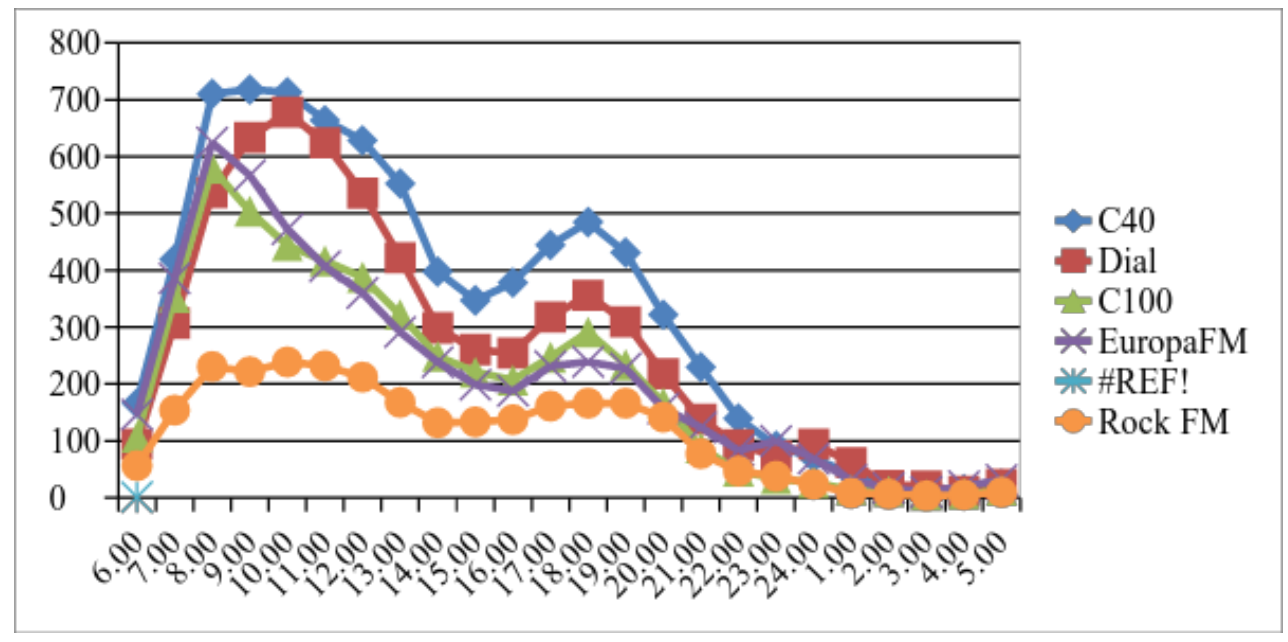

Fuente: Estudio General de Medios, AIMC (2016)

El perfil de la audiencia es diferente según la especialización de las emisoras como muestra el Gráfico 5. Las mujeres son el $65 \%$ de la audiencia de Dial, el $58 \%$ de Cadena 100 y el $56 \%$ de Los 40 . Mientras que los hombres escuchan mayoritariamente Rock FM $(70 \%)$ y Europa FM (52\%).

Gráfico 5: Perfil de audiencia de radio cadenas musicales en España, \% 


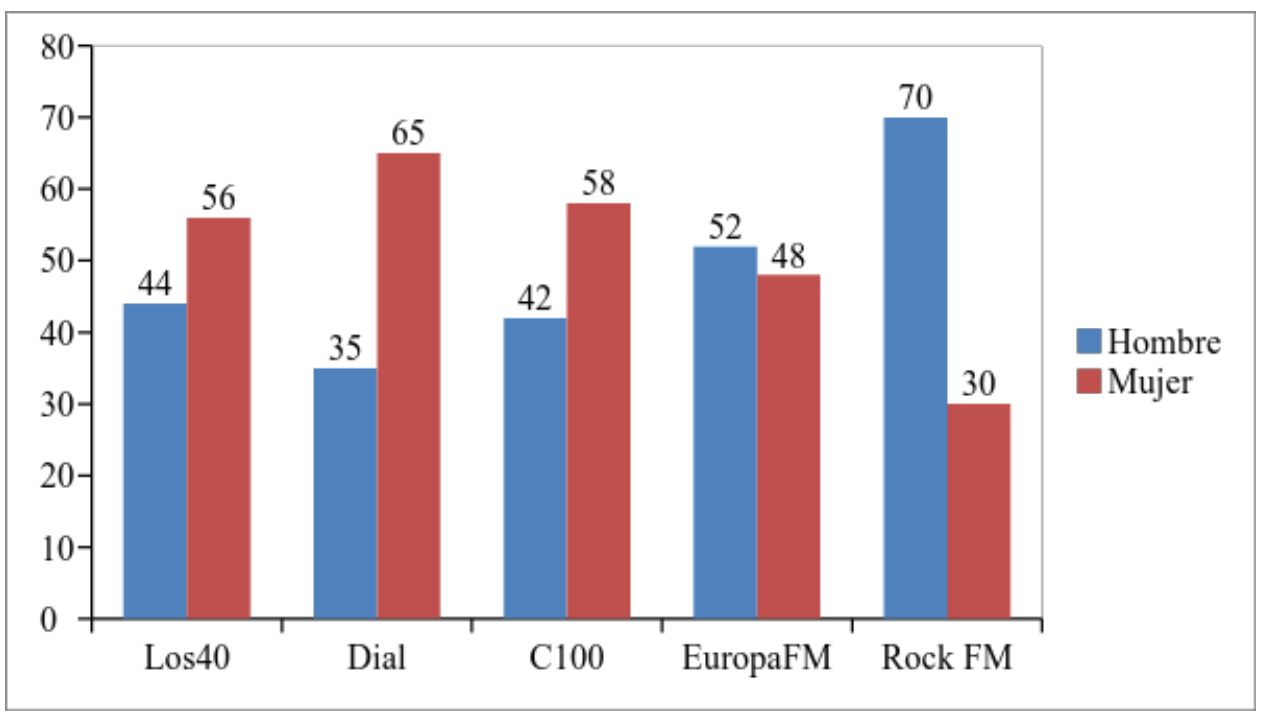

Fuente: Estudio General de Medios, AIMC (2016)

Los intereses musicales son diferentes entre hombres y mujeres, y también por franja de edad como se refleja en el Gráfico 6. Casi el $60 \%$ de la audiencia de Dial, Cadena 100, Europa FM y Rock FM son adultos mayores de 35 años. Los 40 consigue atraer a un $28 \%$ de los jóvenes de 25 a 34 años, y Europa FM a un 23\%. Sin embargo, ninguna consigue sumar más del $12 \%$ de audiencia entre los targets de edad de 14 a 19 años y de 20 a 24 años. Las emisoras musicales que históricamente han interesado a los públicos jóvenes no consiguen con su oferta atraer a estos públicos.

Gráfico 6: Perfil de audiencia de radio cadenas musicales en España según edad, \%

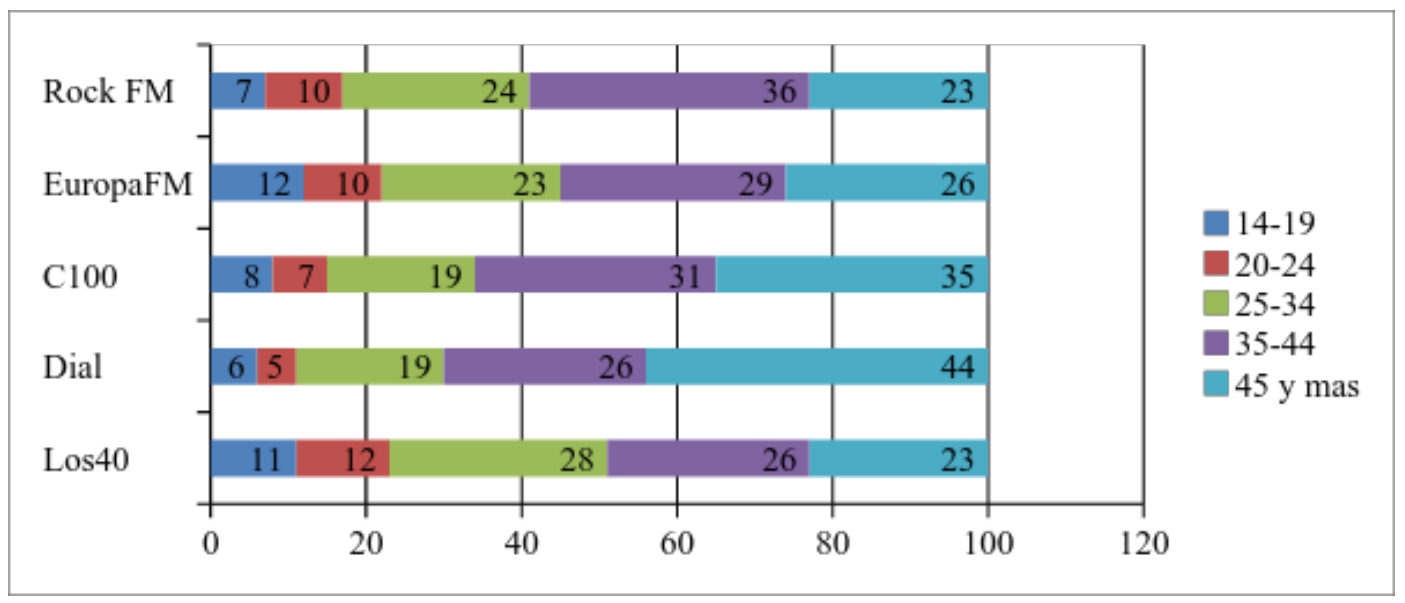

Fuente: Estudio General de Medios, AIMC (2016)

La media de edad es mayor en los últimos cinco años como se recoge en el Gráfico 7, situándose por encima de los 35 años en todas las emisoras. 
Gráfico 7: Evolución media de edad audiencia de radio cadenas musicales en España

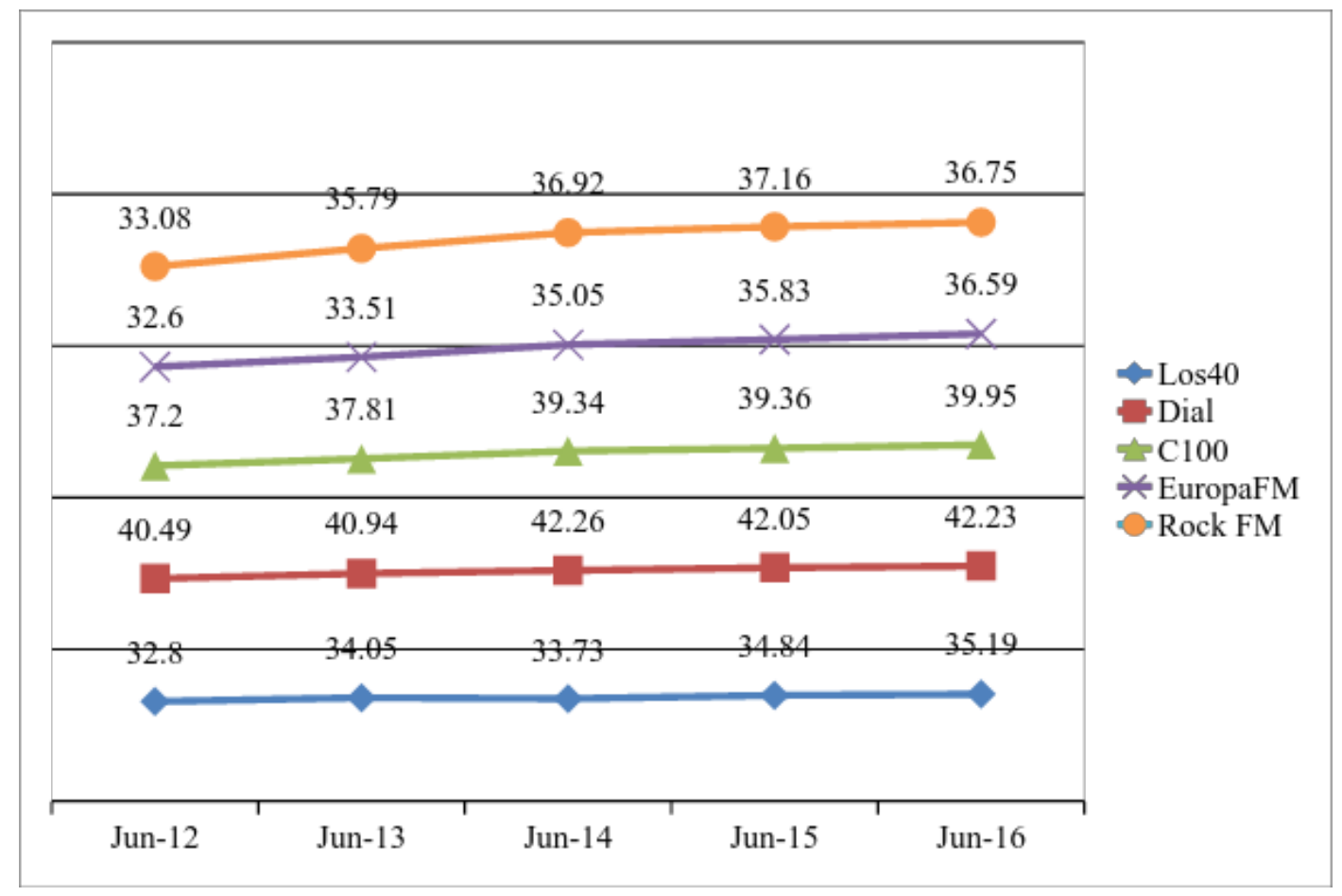

Fuente: Estudio General de Medios, AIMC (2016)

Por perfil socioeconómico, los datos muestran que la mayor parte de la audiencia de radio musical, en torno al $80 \%$ como muestra el Gráfico 8, es del grupo Medio y Medio/Alto. Este comportamiento en España también se produce en las emisoras generalistas.

Gráfico 8: Perfil socioeconómico audiencia de radio cadenas musicales en España, \%

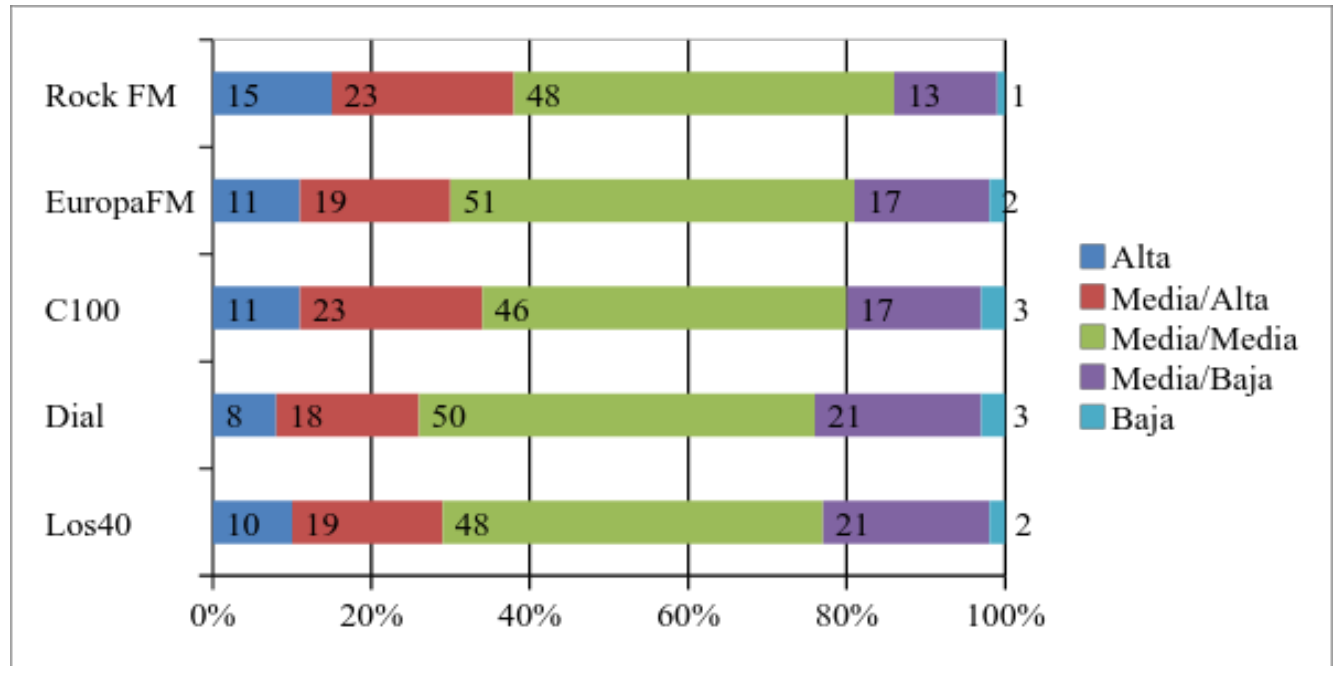

Fuente: Estudio General de Medios, AIMC (2016)

\subsubsection{La audiencia en internet de las radios musicales en España.}

Finalmente, el Gráfico 9 analiza la evolución de la audiencia de estas mismas emisoras en la red y constata que todas mantienen o disminuyen su posición en los últimos 5 años. Los40, de hecho, tras el pico de más de dos millones de usuarios únicos de 2014, se estabiliza en torno al millón y medios de usuarios. Cadena 100, Europa FM y Rock FM también experimentaron incremento ese año para luego disminuir. Solo Dial incrementa de forma muy llamativa sus usuarios en la red en el último año. Aunque se requerirán estudios cualitativos que expliquen con profundidad este aparente estancamiento, la generalización de los registros de usuarios para poder acceder a todos los servicios, así como la competencia de otras plataformas de distribución música se presentan como algunas de las causas. 
Gráfico 9: Evolución audiencia internet cadenas musicales en España, usuarios únicos, por miles

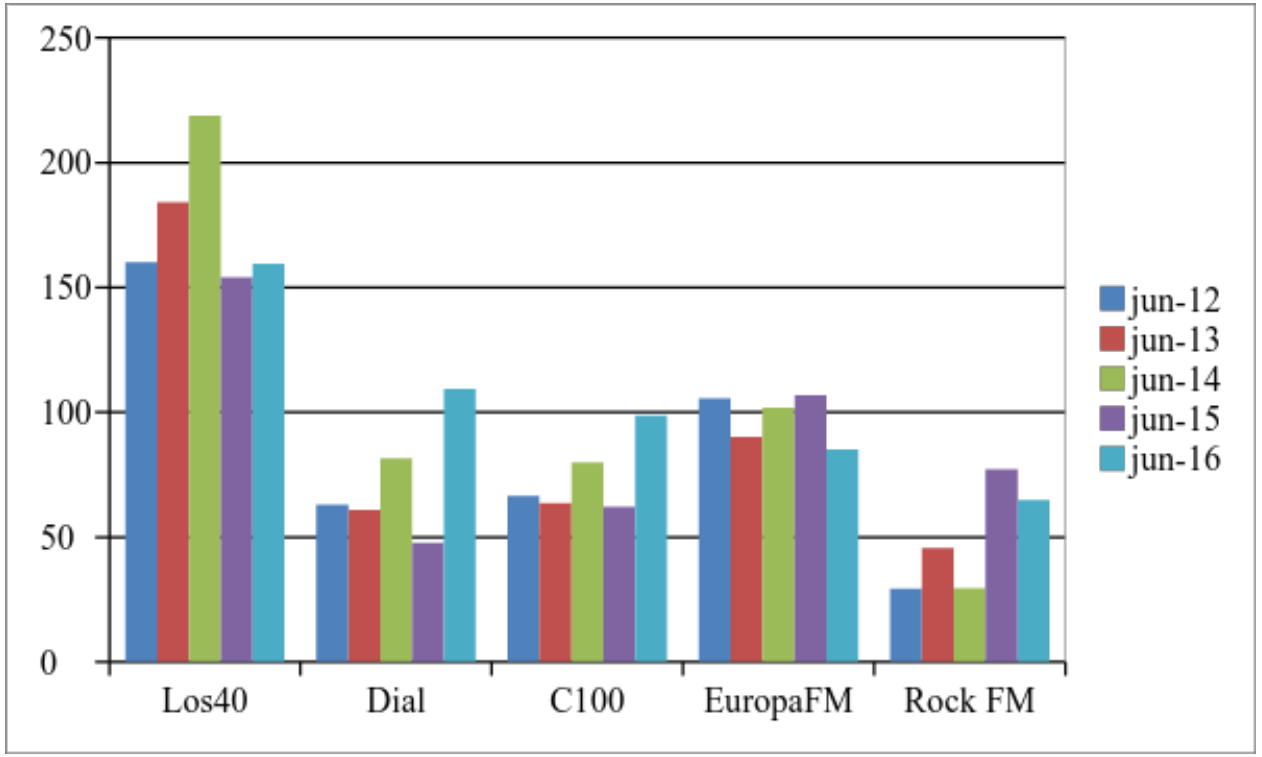

Fuente: Estudio General de Medios, AIMC (2016)

A pesar de los esfuerzos de todas las emisoras por mejorar la experiencia de los usuarios en la red con interfaces más amigables, así como de diversificar sus contenidos y servicios en las redes sociales y las aplicaciones web desarrolladas, los usuarios únicos no se incrementan de manera notable. La estrategia en internet de todas la emisoras ha cambiado, pero los datos no mejoran.

\subsection{El mercado de la radio musical en Argentina}

En la década del 70 llegan al dial las primeras FM, diferenciándose de la AM a partir de locuciones de tonos más bajos y sugerentes, y aportando alternativas a la competencia con la televisión, que ya se había lanzado. La radio musical en la Argentina se hizo notar fuertemente en la década del 80 con la consolidación de la frecuencia modulada, acompañada por las mejoras en la calidad sonora, que convirtieron a la música en contenido central de la programación. Así nacieron y revolucionaron el mercado radiofónico las emisoras especializadas en rock, pop, música extranjera o música clásica: ofrecieron una estética renovada, foco en el contenido musical, conductores con clara intención de diferenciarse, en busca de un oyente cómplice, que integre su nicho. El caso más resonante fue el de Rock and Pop, una emisora que sobresalió desde su creación, en 1985, por su originalidad, rebeldía y profesionalismo, que aún existe, y que lideró la audiencia de la FM durante décadas. En 1989 sobresalió FM Tango, de música ciudadana. La 100 fue una de las que abrió el camino de las radios de formato cerrado, con listas de éxitos, que tuvieron su mejor exponente en FM Hit, hoy conocida como Los40 Principales. FM Aspen fue siempre difusora de música en inglés, también con una impronta bien definida, que conserva hasta nuestros días.

El mercado de la FM creció de modo vertiginoso y se caracterizó por ser tan innovador como cambiante: la mayoría de las emisoras modificó su nombre más de una vez, se mudó de frecuencia o simplemente dejó de existir. Estas variaciones en los nombres muchas veces estuvieron asociadas a cambios de propiedad y de programación. La FM mutó en varias oportunidades acompañando los cambios del mapa de medios de la Argentina fruto de los vaivenes políticos, oscilando entre la promoción de las privatizaciones y creación de grandes multimedios internacionales y la intervención directa del gobierno de turno (Getino, 2006: 196).

En cuanto a los contenidos, en los noventa la FM dejó de tener una propuesta exclusivamente musical y comenzó a programar servicios informativos breves, programas de música y palabra con contenido periodístico, y sumó conductores-periodistas y no solo conductores-locutores. Desde mediados de 2000 la FM se acercó cada vez más a la propuesta de la AM, sobre todo en los horarios de la mañana, en los que hoy abundan los ciclos que combinan información y entretenimiento. En el mercado de la radio argentina existen muy pocas FM especializadas "puras" y, en cambio, muchas emisoras que poseen magacines generalistas con eje en el entretenimiento y el humor, donde la música ocupa un lugar muy importante pero no es la única protagonista.

\subsubsection{La oferta de emisoras musicales más escuchadas en Argentina}

Las emisoras más escuchadas de la Argentina son de capital privado, todas tienen años de historia, y la mayoría lleva tiempo entre las líderes. Como lo muestra la Tabla 2, las radios que concentran la mayor audiencia son Pop Radio, La 100, Disney, Aspen y Metro. 
Tabla 2: Descripción de las cinco emisoras musicales más escuchadas en Argentina, 2015

\begin{tabular}{|l|c|c|c|c|c|}
\hline & Pop Radio & La 100 & Disney & Aspen \\
\hline Tipo de emisora & Comercial & Comercial & Comercial & Comercial & Comercial \\
\hline Titularidad & Indalo & Clarín & Difusora Baires S.A. & Albavisión \\
\hline Programación & AC/Talk Radio & $\begin{array}{c}\text { AC/CHR/Rock/Talk } \\
\text { Radio }\end{array}$ & $\begin{array}{c}\text { CHR } \\
\text { Electrónica/ } \\
\text { Talk Radio }\end{array}$ \\
\hline Ranking & 1 & 2 & 3 & 5 \\
\hline Cuota audiencia & 13,11 & 10,79 & 8,93 & 8,41 \\
\hline Target & Joven/Adulto & Joven/Adulto & Adolesc./Joven & Joven/Adulto & Joven/Adulto \\
\hline $\begin{array}{l}\text { Hora más } \\
\text { escuchada }\end{array}$ & $10-11$ AM & $10-11$ AM & 16 PM 17 PM & $11-12$ AM \\
\hline $\begin{array}{l}\text { Programa más } \\
\text { escuchado }\end{array}$ & Bien Levantado & Lalo Por Hecho & Todos tus Éxitos & Mundo Aspen & Perros de la Calle \\
\hline
\end{tabular}

Pop Radio nació en 2004 con eje en la música pop y, años más tarde, dejó de lado el protagonismo de la música para dárselo a los magacines de entretenimiento. En 2011 consiguió por primera vez aparecer como número 1 del ranking, desplazando a Rock and Pop. "Mañanas campestres", conducido por Santiago del Moro, y "Bien levantado", a cargo de Beto Casella, son los programas más escuchados de la radio en la primera y segunda mañana respectivamente. También por la tarde predominan los magacines con buenas dosis de música y humor. A partir de las 21.00 PM la radio se vuelve más musical. Pop Radio perteneció al Grupo Infobae, de Daniel Hadad, quien en 2012 vendió sus medios al Grupo Indalo, que hoy también cuenta con Radio 10, Mega 98.3 y Vale 97.5. En cuanto a su desarrollo digital, Pop no tiene una página o portal propio, sino que ofrece streaming a través del portal de noticias del mismo grupo de medios del que forma parte, denominado minutouno.com.

La 100 es una emisora que lleva cerca de tres décadas entre las más escuchadas. Desde 1984 emite desde la Ciudad de Buenos Aires con más de 70 repetidoras en todo el país. Pertenece al Grupo Clarín, uno de los multimedios más importantes, que también cuenta con Radio Mitre, la AM que hoy ocupa el primer puesto del ranking de audiencia general. Hubo tiempos en los que La 100 fue, sobre todo, una radio de hits, con locutores presentadores de temas musicales, alta interacción con los oyentes jóvenes. En los 2000 apostó por incorporar magacines fuertes, con conductores de renombre, centrados en el entretenimiento, y sobre todo en los horarios de prime time. Así, desembarcó el primer morning show de la FM, "El show de la noticia". La 100 tiene una programación de bloques, con magacines en los que predomina a la música pero también el contenido, la variedad de voces y, sobre todo, el humor y el entretenimiento. Respecto del desarrollo digital de La 100, el grupo Clarín se adelantó creando Cienradios.com, una plataforma multimedia que ofrece el streaming de sus emisoras tradicionales (Mia, FM del Lago, Mitre, La 100, etc.) y un menú de más de 450 radios online, producidas por el equipo de Cienradios.

Radio Disney propone una radio para adolescentes y jóvenes, que forma parte de Radio Disney Latinoamérica, una cadena presente en Brasil, Chile, Bolivia, Ecuador, Colombia, Costa Rica, República Dominicana, entre otros países. Se trata de una emisora para la familia, con eje en los adolescentes y en la propuesta musical. Emite música pop latina y anglosajona, algo de rock con presencia también de música local. Buena parte de su éxito está en la continuidad: nunca se mueve de los primeros 5 puestos de audiencia. En 2001, abrió el camino para crear la primera Radio Disney en castellano, que hasta entonces sólo existía en Estados Unidos. En su programación se suceden locutores con voces bastante homogéneas, la mayoría mujeres, que buscan que el sonido de la radio sea bastante parecido las 24 horas. Cuenta con el sitio radiodisney.disneylatino.com, desde donde puede escucharse la oferta de la radio a través de la web y material asociado vinculado al universo Disney.

Aspen ofrece una excelente selección de música anglosajona. Es una radio de clásicos que resulta una marca registrada, con un público fiel, que mantiene buenos índices de audiencia a través de los años. Se trata de una de las pocas propuestas del mercado radiofónico argentino en el que la música es la verdadera protagonista; solo se la complementa con alguna información servicio a lo largo del día. A través de los años ha pasado por diferentes propuestas musicales, aunque siempre cercanas a la original. Hoy, se centra en hits y clásicos de la década de los ochenta y noventa. Su programación está estructurada sobre la base de una serie de programas esencialmente musicales, guiados por un locutor, que presenta temas, ofrece información servicio y alienta la participación de los oyentes. Aspen cuenta con el sitio fmaspen.com, que además de la opción de streaming, ofrece mucha información sobre música y concursos.

Radio Metro cambió muchas veces de nombre y estilo hasta adoptar esta denominación en 2002. Desde entonces, giró siempre alrededor del sonido urbano, con eje en la música electrónica, aunque desde hace algunos años los responsables de la música de Metro aseguran que la han llevado a un estilo más "anglo pop". Metro ha conseguido posicionarse fuertemente entre los jóvenes y, gracias a una identidad y una estética bien definida, cuenta con oyentes muy fieles. La programación de Metro ya es un clásico de la FM argentina, sobre todo programas como "Perros de la calle", "Basta de todo" y "Metro y medio", conducidos por referentes de la televisión que hoy son más importantes en la radio. Cuenta con una programación de bloques, enlazada con magacines de entretenimiento, en los que hay mucho trabajo de producción para generar secciones originales. Se trata de una radio que propone creatividad, una estética cuidada, alta participación de la audiencia y mucho humor. Radio Metro cuenta con su plataforma online con una amplia oferta de contenidos complementarios al streaming. El usuario puede recuperar contenido, repasar las secciones de los programas a través de sus blogs, el equipo, fotos e interactuar a través de la página 0 de los enlaces a las redes sociales. 


\subsubsection{La audiencia de las radios musicales tradicionales en Argentina}

La radio musical, que en el caso de Argentina es una radio "música y palabras", desde hace años tiene muy buenos números de audiencia. En el Gráfico 10 se evidencia que la FM supera ampliamente a la OM o generalista en casi todas las franjas horarias. Se acercan entre las 6.00 y las $9.00 \mathrm{AM}$ y en los horarios nocturnos. El pico de audiencia de ambas se da alrededor de las 10.00 $\mathrm{AM}$, horario donde el encendido supera los 40 puntos.

Gráfico 10. Audiencia AM, FM y total, cuota según hora del día

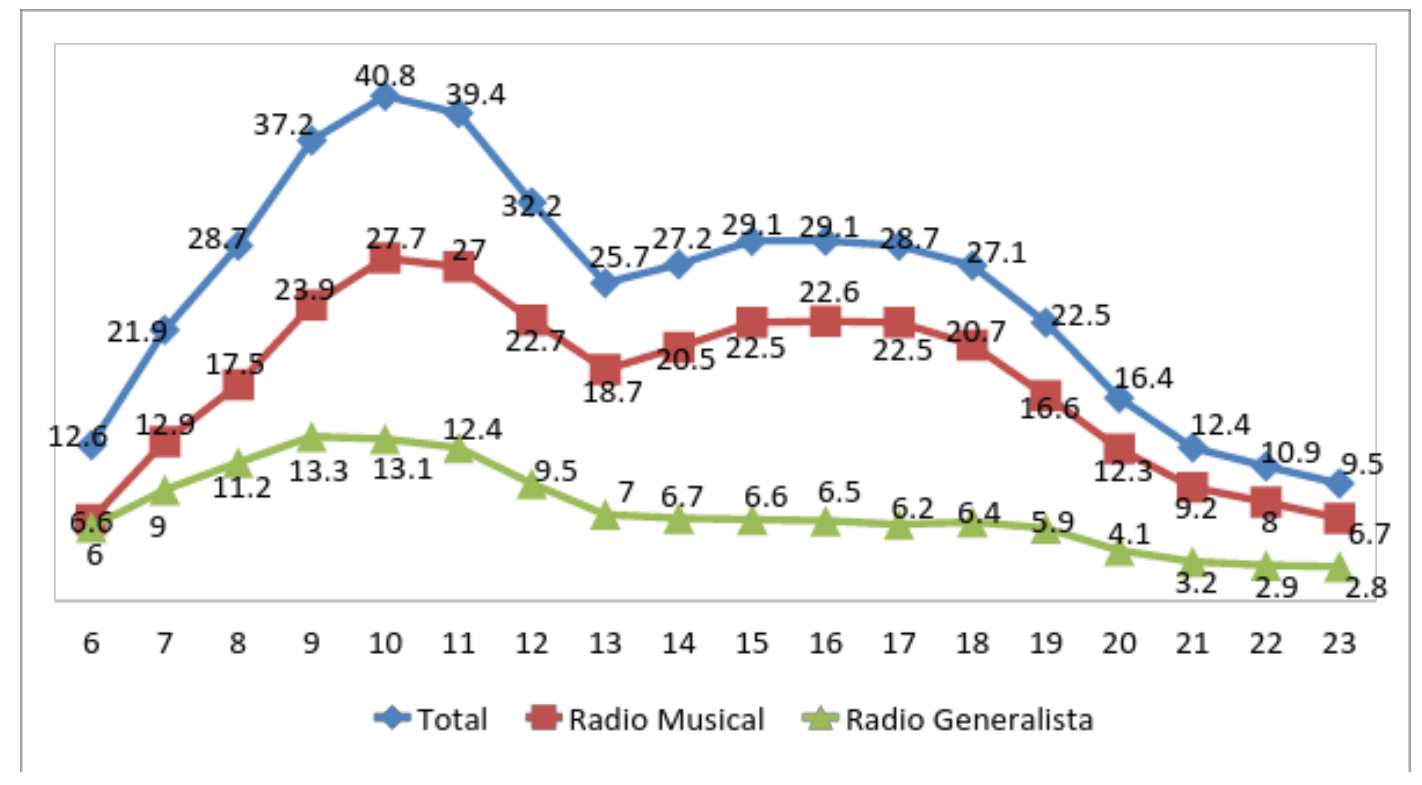

Fuente: Kantar Ibope Media (2014)

Se puede observar que la FM tiene su pico de audiencia a las $10.00 \mathrm{AM}$, con una cuota del 27,7, seguido por la franja de las 11.00 y de las $9.00 \mathrm{AM}$. Es decir que, entre las 9.00 y las $11.00 \mathrm{AM}$, se concentra el mayor encendido de FM en la Argentina.

Desde el mediodía la curva es descendente, con excepción entre las 15.00 y 17.00 PM, en donde sube levemente hasta un 22,6 de share para luego ir bajando progresivamente hasta las 23.00 PM, con el índice más bajo: 6,7.

Si se analiza la curva de encendido diaria de las emisoras más escuchadas, tomando los meses transcurridos de 2016 hasta la fecha, el Gráfico 11 muestra que en algunas radios se repite el dibujo del encendido general de FM: más audiencia por la mañana y caída de la escucha desde el mediodía. Sin embargo, Radio Disney es la excepción, con mayor audiencia entre las 15.00 y las 18.00 PM, haciendo pico a las 16.00 PM, con 2,5\% de share. Aspen también es un caso diferente, porque sus picos de audiencia con a las $11.00 \mathrm{AM}$ y las $15.00 \mathrm{PM}$, con $1,8 \%$.

Gráfico 11. Evolución audiencia diaria emisoras más escuchadas en Argentina, cuota

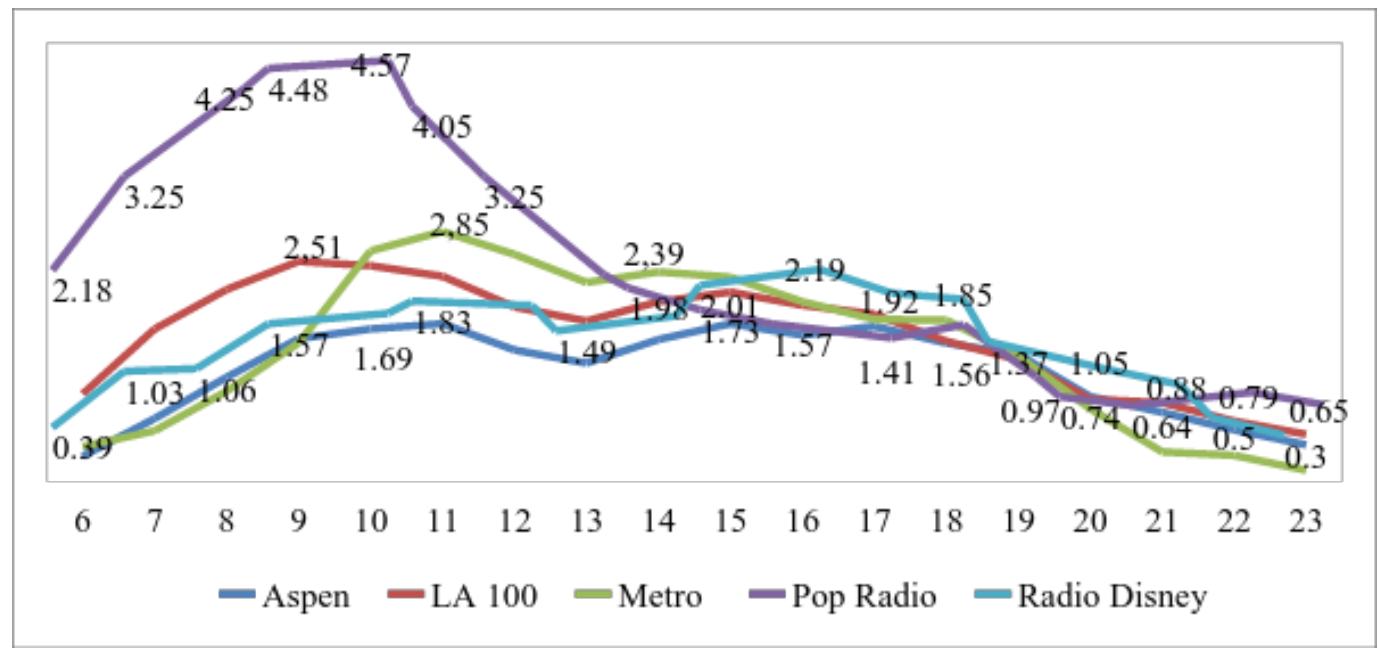

Fuente: Kantar lbope Media (2016) 
También hay que destacar la ventaja en audiencia que saca Pop Radio por la mañana. Desde las 6.00 AM, con 2,18\% de cuota se distancia del resto hasta alcanzar un pico de 4,57 a las $10.00 \mathrm{AM}$. Vale mencionar que esta misma emisora llega a ubicarse última, a las 19.00 PM, con 0,97. Se puede concluir que tiene un público fiel a los programas de la mañana, algo que no le sucede al resto de las radios líderes. Todas cuentan con una curva más estable, con distancias menos abruptas entre los diferentes horarios. Un ejemplo de estabilidad es La 100, con un pico a las 9.00 AM con 2,51\% y, luego de una leve caída al mediodía, vuelve a subir entre las 14.00 y las 17.00 PM. Se trata de una emisora que conserva buenos números de audiencia en todas las franjas. Metro crece en audiencia abruptamente a las 10.00 AM, horario en el que arranca "Perros de la Calle", el programa más escuchado de Metro y el segundo más escuchado a esa hora en FM. Entre las 13.00 y las 15.00 PM, Metro lidera la escucha de FM, seguida por La 100. Conserva un buen número de audiencia por la tarde, donde pelea al liderazgo con Disney y La 100. En definitiva, las 5 radios son muy competitivas entre sí, especialmente por la tarde, cuando todas se acercan en audiencia, mientras que por la mañana hay más distancia entre ellas.

Si analizamos la evolución de la audiencia de las 5 emisoras entre 2011 y 2016, en el Gráfico 12 se observa un liderazgo por parte de La 100 hasta 2014, cuando Pop Radio consigue superarla y La 100 pasa a ocupar un cómodo segundo lugar, distante todavía del resto.

Gráfico 12. Evolución audiencia emisoras más escuchadas en Argentina, cuota

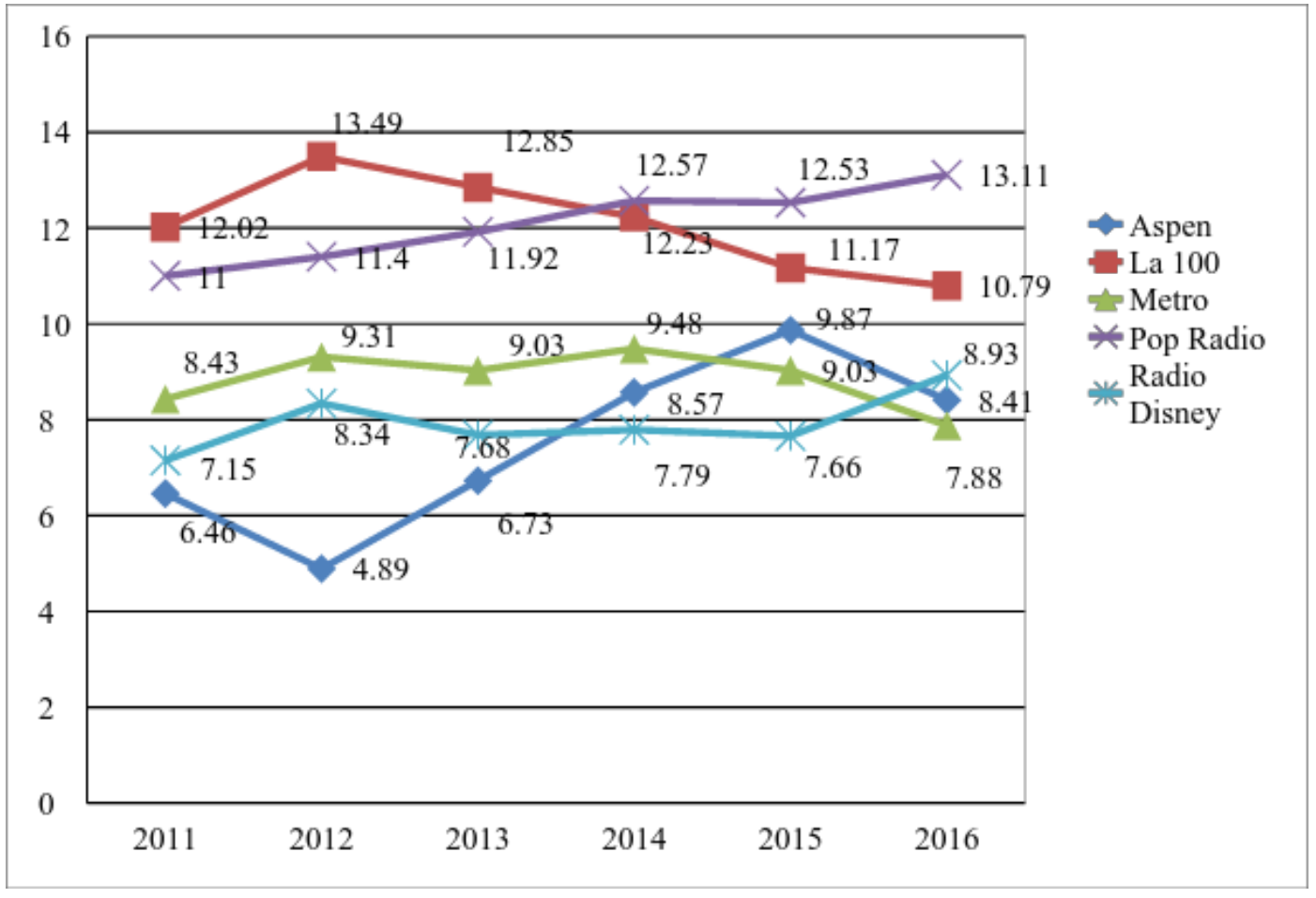

Fuente: Kantar Ibope Media (2016)

Vale destacar el caso de Aspen, que pasó de estar quinta en 2011, con 6,46\% de cuota, a ubicarse tercera, con 9,87 en 2015. Teniendo en cuenta los meses transcurridos en 2016, este año se ubicaría cuarta, detrás de Disney. Radio Disney se mantuvo muy estable en los últimos años, siempre entre el tercer y cuarto lugar, con una importante subida en el último año, hasta alcanzar un $8,93 \%$ de share.

El Gráfico 13 muestra la evolución de la audiencia acumulada entre 2011 y 2016. La 100 cuenta con más de 931 mil oyentes, seguida por Pop, con cerca de 897 mil. Aspen tiene 10 mil oyentes menos que Pop, y se ubica delante de Radio Disney y de Metro, con 812 mil y 538 mil oyentes, respectivamente. Aspen casi duplicó su audiencia entre 2012 y 2014. 
Gráfico 13. Evolución audiencia radio en Argentina por cadenas musicales, por miles

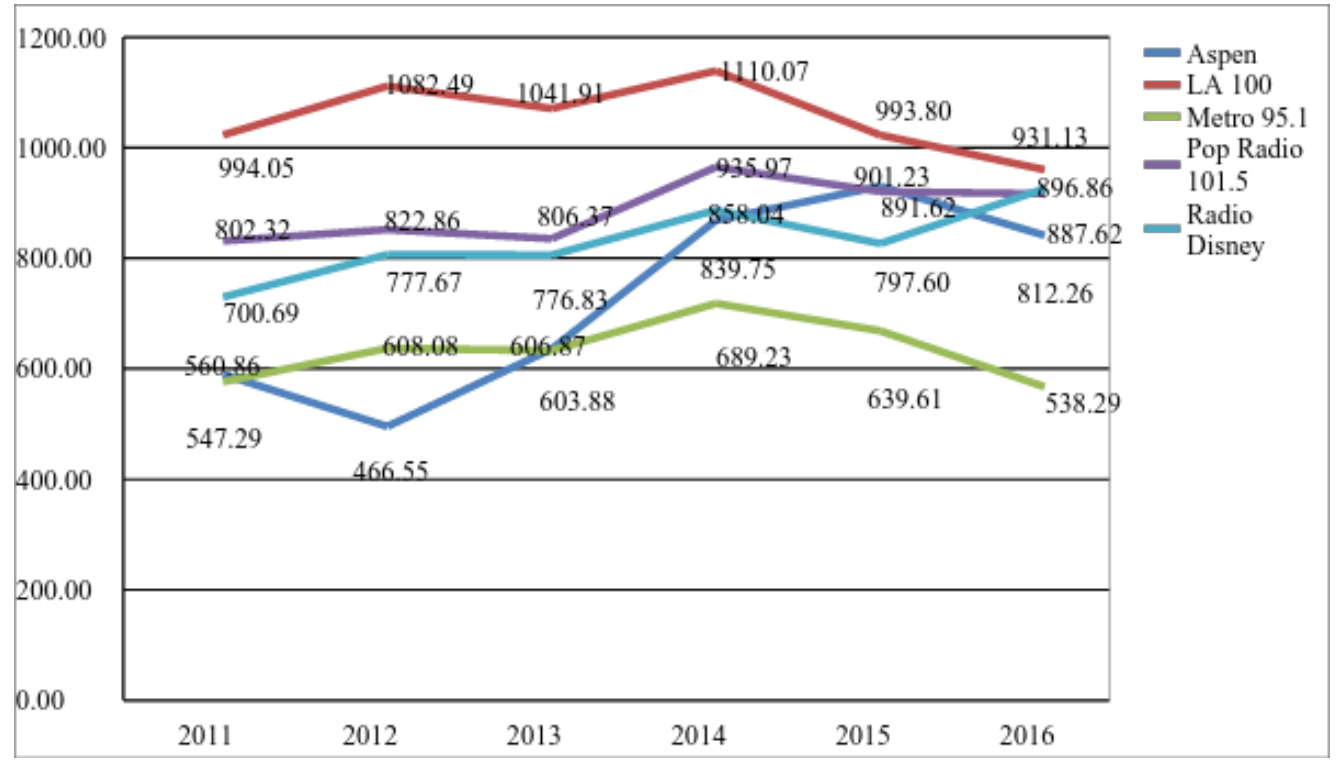

Fuente: Kantar Ibope Media (2016)

\subsubsection{La audiencia en internet de las radios musicales en Argentina}

El desarrollo digital de las 5 emisoras líderes ha sido muy diverso. Todas implementaron portales con streaming, contenidos de descarga atemporal, interacción con el usuario, enlace con las redes sociales y aplicaciones. Pero algunas se diferenciaron por crear productos digitales total o parcialmente independientes de la radio tradicional. Quizá el caso más destacado sea el de Cienradios.com, que creó un producto digital nuevo, con más de 500 emisoras online de 24 horas de música. Si bien aún no se conocen cifras oficiales que nos permitan comparar el funcionamiento de los desarrollos digitales de las diferentes radios, ComsCore ofrece algunos datos de radios online como Cienradios, Aspen, Vorterix, Gamba FM y Metro. No tenemos referencias de Pop y de Radio Disney.

Gráfico 14. Evolución audiencia internet cadenas musicales en Argentina, usuarios únicos, por miles

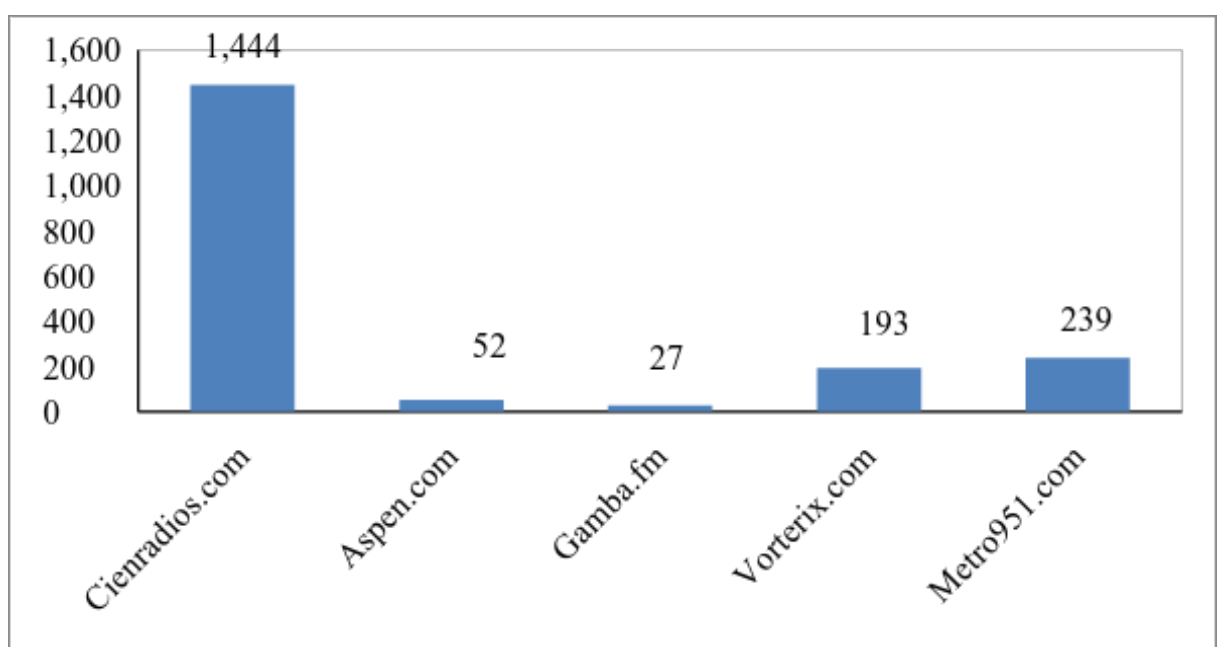

Fuente: Elaboración propia según datos de ComsCore (2016)

El Gráfico 14 muestra que Cienradios cuenta con una enorme ventaja respecto del resto. Tiene casi un millón y medio de usuarios únicos en lo que va de 2016. En segundo lugar se posiciona Metro, con 239 mil usuarios únicos, seguida por Vorterix, con 193 mil. Aspen, con 52 mil y Gamba con 27 mil figuran cuarta y quinta. El producto Cienradios se adelantó al resto de la oferta digital ofreciendo numerosas emisoras online que le facilitan un buen tráfico de usuarios. Vorterix es una emisora que nació digital, aunque también emite por una frecuencia. Gamba FM es una radio exclusivamente online.

El Gráfico 15 permite sacar conclusiones en relación con el rango de edad de los usuarios de estas emisoras online. La 100, Gamba FM, Metro y Vorterix concentran su mayor púbico entre los 25 y los 34 años. En cambio, la mayoría de los usuarios de Aspen tienen 45 años y más. 
Gráfico 15. Usuarios de radio online en Argentina, según edad, por miles

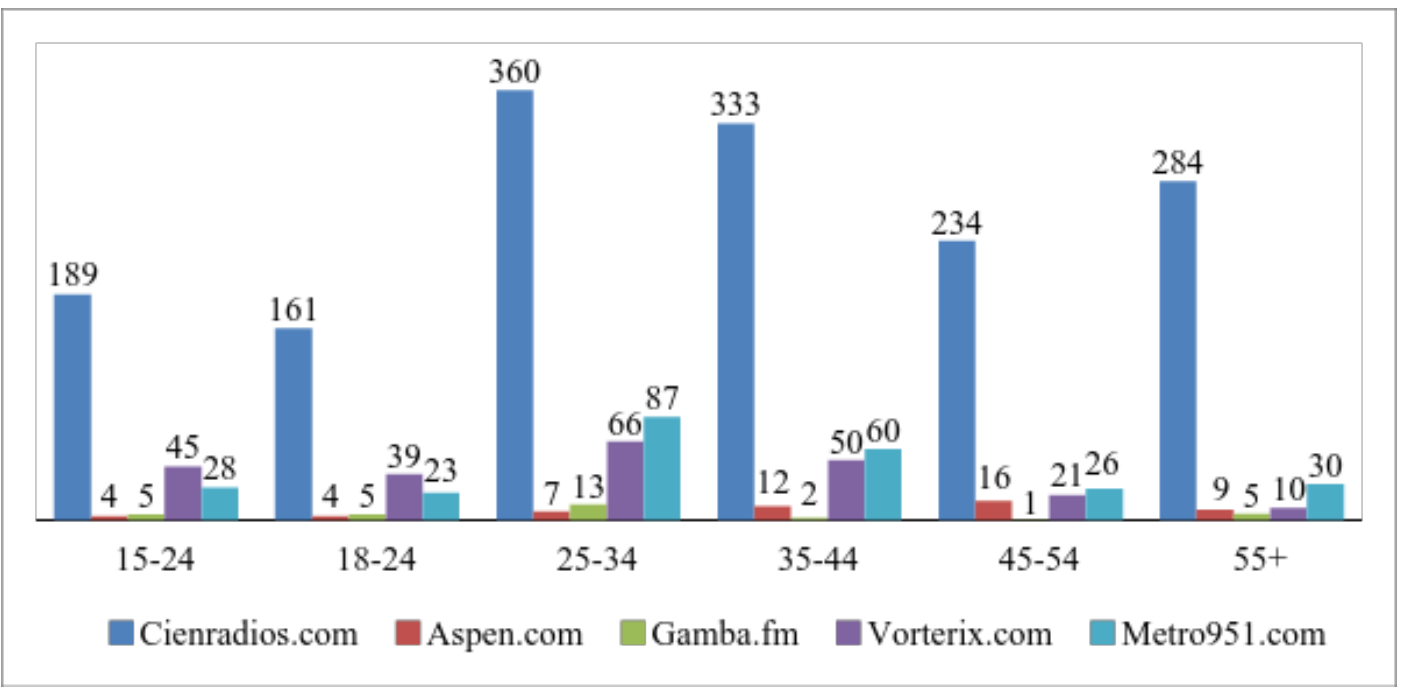

Fuente: Elaboración propia según datos de ComsCore (2016)

En cuanto al sexo y la edad de los usuarios, el Gráfico 16 nos revela que el público que más consume Cienradios es el de mujeres entre 25 y 34 años y 35 y 44 años, aunque también cuenta con una buena proporción de usuarios varones. Los que menos la consumen son los jóvenes entre 15 y 24 años.

Gráfico 16. Usuarios de radio online según sexo y edad en Argentina, por miles

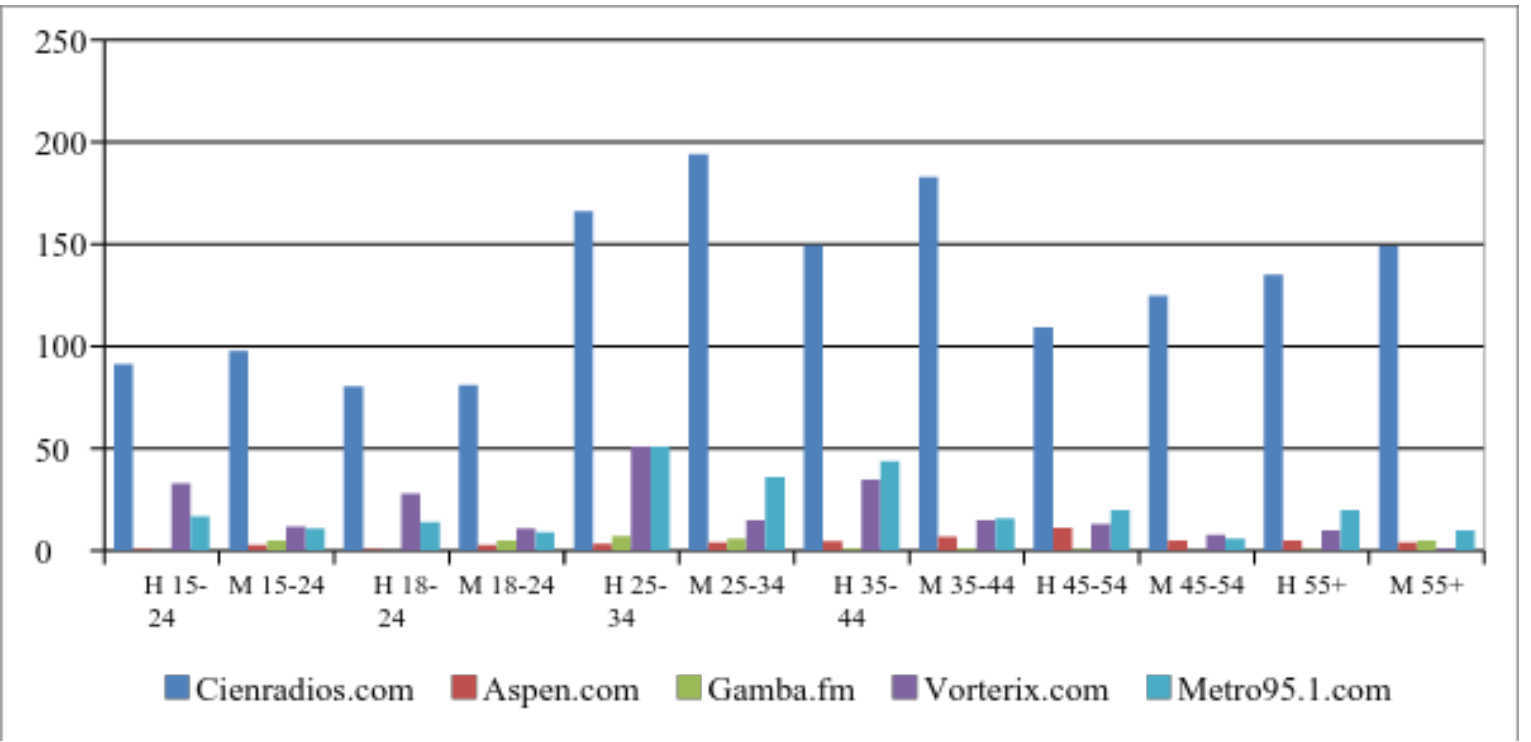

Fuente: Elaboración propia según datos de ComsCore (2016)

Radio Metro, en cambio, tiene un público más masculino, especialmente entre 25-34 años y 35-44 años. Vorterix muestra más distancia aún entre el consumo masculino y femenino. Es un producto más consumido por hombres entre 25 y 44 años. Aspen también tiene más usuarios hombres y es escuchada, en primer lugar, por varones de 45 a 54 años y, en segundo lugar, por mujeres que entre los 35 y 44 años.

Estos datos, aún insuficientes para tener un panorama más claro sobre el desempeño de los productos radiofónicos digitales, ofrecen algunas pistas que nos permiten sacar breves conclusiones. El desarrollo de productos online todavía está en una fase preliminar en el sector de la radio, hay muchas diferencias entre la oferta de una emisora y otra, y las radios tradicionales aún no explotan del todos las posibilidades que le ofrece el mundo digital al medio tradicional.

\section{Conclusiones: Hacia un nuevo modelo de radio musical}

La radio musical en España y Argentina acumula más oyentes que la radio generalista, y el prime time se ubica durante la mañana, también el horario en el que más compite con la OM. El prime time de la radio española empieza más temprano $(8.00$ AM) y se extiende por más horas (hasta las 13.00 PM). En Argentina, en cambio, comienza a las $9.00 \mathrm{AM}$ y se extiende hasta las 
12.00 PM. Las emisoras musicales además tienen un segundo pico de audiencia por la tarde, donde algunas de ellas también empiezan a incluir programas de acompañamiento y humor, bien complementados con la música.

Buena parte de este comportamiento de la audiencia tiene que ver con el éxito de los denominados morning shows y los programas del drive time vespertino, que se han generalizado en todas las emisoras estudiadas y consiguen atraer audiencia. La música se mezcla con los programas. La radio Argentina cuenta solo con dos emisoras puramente musicales entre las líderes: Aspen y Disney. Las demás, ofrecen una programación de magacines en casi todas las franjas horarias. Son radios "música y palabra", en las que ambos recursos expresivos se alternan de modo constante. Las emisoras musicales de formato "puro" y las especializadas temáticas nunca han funcionado en el mercado argentino. Por ello, la mayoría incorpora mucho contenido hablado a través de programas.

Entre las radios musicales líderes las emisoras de hits son minoría, y los datos revelan que pierden oyentes progresivamente. El caso más notable es del de Los40, emisora líder en España, que muestra una notoria caída de audiencia. En Argentina, Los40, también emisora del grupo Prisa, no se ubica hoy entre las 5 primeras. Aunque La 100 y Disney, sobre todo, trabajan con listas de éxitos y ponen al aire hits del momento, no basan en ellos su estilo musical. Las emisoras que han propuesto formatos no habituales en su mercado, han conseguido atraer audiencia y consolidarla, como es el caso Rock FM en España.

Tanto en España como en Argentina tres de las emisoras líderes cuentan con formato musical Adulto Contemporáneo, en el caso del país latinoamericano implementado no de un modo "puro" y, en algunas emisoras, en convivencia con una programación de magacines durante todo el día. En ambos países entre las emisoras más escuchadas hay radios de formato AC, tanto español como internacional.

Ambos mercados muestran que las radios tradicionales líderes aún no aprovechan todas las alternativas que les ofrece el entorno digital. Todas ofrecen el mismo contenido por streaming, aplicaciones y uso de redes sociales, pero muy pocas destacan en el mercado agregando valor añadido a la oferta tradicional gracias a las posibilidades que ofrece lo digital.

En el caso de España, un número que deja en evidencia la falta de innovación es el statu quo en el que se mantiene la cantidad de usuarios de todas las emisoras líderes. En Argentina, sobresalen más los productos nuevos (Cienradios, Vorterix) que los desarrollos digitales de las radios ya existentes. El usuario encuentra más opciones de servicios de música a la carta fuera de la oferta digital de las emisoras tradicionales.

Las radios musicales tradicionales no llegan a los públicos más jóvenes. Los oyentes no crecen en número, se trasladas de una cadena a otra 0 se desenganchan. Esto puede ser el resultado de la migración de las audiencias nativas digitales hacia plataformas como spotify, youtube, etc. Esto lleva a preguntarse si es viable competir con las listas automatizadas, los catálogos de emisoras y las plataformas de distribución de música y vídeo ofreciendo servicios similares. Más aún, si se constata que las acciones hechas en el entorno online no han incrementado la audiencia.

El nuevo modelo de radio musical que hay que diseñar deberá tener en cuenta estas consideraciones y avanzar en el valor añadido que puede aportar en un entorno de multiplicación de servicios de audio musical.

\section{Bibliografía}

Alonso, González, M. (2015). Radio y Redes sociales: La interactividad radiofónica en los Morning Shows en España. Estudios sobre el Mensaje Periodístico, 21 (2), 689- 704. Madrid, Servicio de Publicaciones de la Universidad Complutense.

Amoedo, A.; Martínez-Costa, M.P.; Moreno, E. (2008). An analysis of the communication strategies of Spanish commercial music networks on the web: http://los40.com, http://los40principales.com, http://cadena100.es, http://europafm.es and http://kissfm.es. The Radio Journal: International Studies in Broadcast \& Audio Media 6 (1), 5-20.

AIMC (2015 y 2016): Estudio General de Medios. Madrid: Asociación para la Investigación de Medios de Comunicación. [http://www.aimc.es/-Que-es-el-EGM-.html]

Balsebre, A. (2002). Historia de la radio en España. Volumen II (1930-1985). Madrid: Cátedra.

Cebrián Herreros, M. (2007). Modelos de radio, desarrollos e innovaciones. Madrid: Fragua.

Costa Gálvez, Lola (2013). "Como lo oyes. La publicación de listados de reproducción de los programas temáticos musicales en la radio de titularidad pública en España". Trípodos 33, 73-98.

Elizalde, Luciano (2002), "La Argentina del siglo XX". Nueva Historia de la Nación Argentina, tomo 9,363-394, Buenos Aires: Planeta.

Faus Belau, A. (2007). La radio en España (1986-1077). Una historia documental. Madrid: Taurus.

Kantar Ibope Media Argentina (2015 y 2016). http://www.kantaribopemedia.com.ar/ibope/wp/radio

Getino, Octavio (1995). Las industrias culturales en la Argentina. Buenos Aires: Ediciones Colihue.

Getino, Octavio (2016). El capital de la cultura. Las industrias culturales en Argentina y en la integración del Mercosur. Buenos Aires: Publicaciones del Senado de la Nación.

Gutiérrez, M., Ribes, X., \& Monclús, B. (2011). La audiencia juvenil y el acceso a la radio musical de antena convencional a través de internet. Comunicación Y Sociedad, 24(2), 305-331. Pamplona: Servicio de Publicaciones Universidad de Navarra. 
López, Vidales, N.; Gómez Rubio, L.; Redondo García, M. (2014). "La radio de las nuevas generaciones de jóvenes españoles: Hacia un consumo on line de música y entretenimiento". ZER Revista de Estudios de Comunicación, 19 (37), 45-64. Bilbao: UPV/EHU.

Martí, J.M. (1990). Modelos de programación radiofónica. Barcelona: Feed Back Ediciones.

Martí, J.M. (2000). "Reflexiones sobre la radio musical del futuro". En Pedrero, L. La radio musical en España: historia y análisis. Madrid: Instituto Oficial de Radio y Televisión RTVE, pp. 241-245.

Martí, J.M. (2004). "La programación radiofónica". En Martínez-Costa, M.P.; Moreno, E. Programación radiofónica: arte y técnica del diálogo entre la radio y su audiencia. Barcelona: Ariel, pp. 20-46.

Martínez-Costa, M.P.; Moreno, E. (2004). Programación radiofónica: arte y técnica del diálogo entre la radio y su audiencia. Barcelona: Ariel.

Martínez-Costa, M.P.; Prata, N. (2016). "O rádio em busca da sua audiência: rumo a uma escuta diversificada e multiplataforma". XXXIX Congresso Brasileiro de Ciências da Comunicação, Intercom, Sociedade Brasileira de Estudos Interdisciplinares da Comunicação, São Paulo. http://portalintercom.org.br/anais/nacional2016/resumos/R11-15301.pdf

Moreno, E. (1999). La radio de formato musical: concepto y elementos fundamentales. Comunicación y sociedad 12 (1), 89-111.

Moreno, E. (2005). Las radios y los modelos de programación radiofónica. Comunicación y sociedad 18 (1), 61-111.

Pedrero, L. (2000). La radio musical en España: historia y análisis. Madrid: Instituto Oficial de Radio y Televisión RTVE.

Sellas, T. (2011). "Repositorios sonoros". El profesional de la información 21 (2), 206-209.

Wall, T. (2004). "The political economy of internet music radio". The Radio Journal: International Studies in Broadcast \& Audio Media 1 (2), 27-44.

Cómo citar este artículo en bibliografías - How to cite this article in bibliographies / references:

MARTÍNEZ-COSTA, M. P.; MÜLLER, M. J. (2017): "El futuro de la radio musical en el entorno digital en Argentina y España". En Revista de la Asociación Española de Investigación de la Comunicación, vol. 4, número 7, pp. 86-101. 